\title{
"O QUE NOSSO TEMPO MAIS PRECISA": KIERKEGAARD E O PROBLEMA DAS CATEGORIAS NA FILOSOFIA DO SÉCULO XIX*
}

Gabriel Ferreira da Silva** gabrielferreira@unisinos.br

RESUMO Nos últimos anos, a literatura acerca da filosofia do século XIX tem apresentado uma reavaliação, tanto no que diz respeito a seus problemas e movimentos, quanto ao papel de determinados filósofos no interior daquele panorama. Com o objetivo de evidenciar a contribuição empreendida pelo filósofo dinamarquês Søren Kierkegaard (1813-1855) ao contexto geral da virada anti-Hegel em meados daquele século, este artigo analisa os problemas referentes às categorias como loci da tese idealista da unidade entre lógica e ontologia a partir da critica kierkegaardiana e de seu tratamento de tais problemas.

Palavras-chave Kierkegaard, categorias, Hegel, Lógica, Ontologia.

ABSTRACT In recent years, secondary literature about $19^{\text {th }}$ Century philosophy has shown a reassessment of both its problems and movements, as well as the role of some philosophers within that scenario. In order to make explicit the contribution undertaken by the Danish philosopher Søren Kierkegaard (1813-1855) to the general context of the anti-Hegelian turn in the middle of that century, this article analyzes the problems concerning categories as the loci

* Agradeço ao Prof. Dr. Mario Porta, bem como ao grupo de pesquisa Origens da Filosofia Contemporânea (PUC-SP), no qual a primeira versão deste texto foi apresentada e debatida. Agradeço igualmente ao Prof. Dr. Thiago Faria, pelas sugestões ao manuscrito.

** Universidade do Vale do Rio dos Sinos - UNISINOS. Artigo recebido em 11/03/2016 e aprovado em 30/05/2016 
of idealistic thesis of unity between logic and ontology as from Kierkegaard's critique and approach to such problems.

Keywords Kierkegaard, categories, Hegel, Logic, Ontology.

Em 1845, durante o processo de confecção do que viria a ser o "Pósescrito conclusivo não científico às Migalhas Filosóficas", publicado em 1846, Kierkegaard fez a seguinte anotação em seus diários:

Muito provavelmente o que nosso tempo [ vor Tid] mais precisa para iluminar [belyse] a relação entre lógica e ontologia é de um exame dos conceitos: possibilidade [Mulighed], atualidade [Virkelighed] e necessidade [Nødvendighed]. Espera-se, no entanto, que a pessoa que fará algo nesse sentido seja influenciada pelos gregos. A sobriedade grega é raramente encontrada nos filósofos dos nossos dias e a engenhosidade excepcional é apenas um medíocre substituto. Bons comentários são encontrados nas Logische Untersuchungen de Trendlenburg [sic]; mas Trendlenburg foi também moldado pelos gregos (Pap. VI B 54:21 n.d., 1845). ${ }^{1}$

O excerto contém ao menos quatro afirmações importantes:

a. um juízo sobre "nosso tempo";

b. um juízo acerca da necessidade de clarificação das relações entre lógica e ontologia;

c. que tal clarificação requer uma análise das categorias modais e, por fim, que;

d. tal clarificação deve ser empreendida por alguém "influenciado pelos gregos", sendo Trendelenburg um de seus exemplos.

Tomadas em conjunto, as quatro asserções não apenas deixam entrever certo julgamento, assim como uma prescrição de Kierkegaard para a filosofia de seu tempo, mas, do ponto de vista do contexto filosófico de meados do século XIX, o posicionamento do filósofo dinamarquês apontado nessa nota mostra uma conexão profunda com certo conjunto de problemas fundamentais para o quadro de questões filosóficas mais gerais do que aquele no qual Kierkegaard

1 "Pap" refere-se à edição dinamarquesa dos diários e papéis de Kierkegaard: "Søren Kierkegaards Papirer", Vols. 1-16, editado por P. A. Heiberg, V. Kuhr e. Torsting. Copenhagen: Gyldendal, 1909-1948; complementado por Niels Thulstrup. Copenhagen: Gyldendal, 1968-1978. Todas as traduções de escritos de Kierkegaard neste artigo, tanto do inglês quanto do dinamarquês, são minhas. 
é geralmente incluído. Desse modo, o objetivo deste artigo é, a partir de uma breve exposição do panorama filosófico da filosofia do XIX após Hegel e da centralidade da discussão acerca do problema das categorias na medida em que esse se constitui como o locus privilegiado das questões acerca da relação entre Lógica e Metafísica, apontar as contribuições de Kierkegaard para tal status quoestionis. Por último, à guisa de conclusão, indicarei algumas possíveis contribuições à compreensão do conceito de Categoria no interior da obra de Kierkegaard.

\section{O "nosso tempo": a virada anti-Hegel e o problema das categorias como locus da relação entre lógica e ontologia}

A filosofia do século XIX recebe tradicionalmente um tratamento que se poderia chamar de esquizofrênico: se, por um lado, há o inegável reconhecimento de que existem no período nomes cujas obras são incontornáveis, assim como uma miríade de problemas, teses e posições fundamentais mesmo para a filosofia subsequente; por outro, essa mesma visão tradicional dos movimentos e debates passa ao largo de uma série absolutamente não desprezível de questões que engendraram as principais contribuições filosóficas daquele período. No tocante a Kierkegaard e suas eventuais colaborações, a concepção tradicional, tanto sobre seu papel no panorama mais geral quanto sobre o escopo de problemas com os quais ele estaria interessado ou teria alguma contribuição a oferecer é particularmente limitada.

A visão canônica acerca da Filosofia do século XIX é comumente construída a partir da leitura de Karl Löwith, exposta em sua clássica obra de 1941, "Von Hegel zu Nietzsche: Der revolutionäre Bruch im Denken des neunzehnten Jahrhunderts" (De Hegel a Nietzsche - a revolução no pensamento do século XIX). Segundo Löwith, a história da filosofia do século XIX é a história da grande reação a Hegel - exposta sem maiores determinações internas - empreendida pelo trinômio Kierkegaard, Marx e Nietzsche. ${ }^{2}$ Se, por um lado, Kierkegaard é tido como um dos personagens centrais do grande arco traçado por Löwith, por outro, a caracterização do autor alemão deixa de fora eventos que se provariam cruciais para o desenvolvimento posterior da Filosofia, como o Neokantismo fundamental a nomes aparentemente tão opostos quanto Carnap e Heidegger ${ }^{3}$-,

2 Löwith faz referência marginal também a Ludwig Feuerbach, Max Stirner e Bruno Bauer. Contudo, Löwith vê naqueles três as figuras-chave da revolução do período.

3 Tendo Löwith sido aluno de Heidegger, tal ausência é particularmente notória. Sobre Heidegger, Carnap e o Neokantismo, veja-se Friedman (2000). 
as querelas em torno do Historicismo, do Materialismo, bem como o surgimento da lógica moderna e os tópicos que orbitam em redor deste último. Löwith sequer menciona nomes como Frege, Bolzano e Brentano ${ }^{4}$ e só de passagem toca em nomes como Trendelenburg e Herbart. ${ }^{5}$ Dessa forma, se sua apreciação da importância de Kierkegaard para o escopo de questões de sua época é positiva, a amplitude de seu papel para a filosofia do XIX, entretanto, fica, por conta da limitada perspectiva de Löwith, restrita à crítica a Hegel e, isso, de maneira muito pouco matizada. ${ }^{6}$

Contudo, para além da visão tradicional de Löwith, as últimas décadas têm conhecido um crescente e renovado interesse geral pela filosofia do século XIXcom trabalhos como os de Freuler (1997), O’Hear (1999), Moyar (2010) e Beiser (2014) -, bem como por suas questões mais específicas e conexões de influência e gênese dos problemas contemporâneos - como é o caso de Dummet (1996), Glock (1997), Friedman (2000), Porta (2005; 2011) e Beiser (2013; 2015). Com isso, os papéis, obras e filósofos têm passado por uma profunda reavaliação, trazendo à tona algumas questões e problemas ou mesmo diferentes facetas de temas aparentemente cristalizados. ${ }^{7}$ Entre esses últimos, encontra-se o tema da virada anti-Hegel e sua relação com o renovado interesse no categorialismo.

Que a segunda metade do XIX tenha sido marcada por uma rejeição ao idealismo hegeliano é um tópos claro e distinto. O que é menos evidente é que o movimento de afastamento desdobrou-se em uma miríade de temáticas. De importância cabal é identificar aquilo que já H. Schnädelbach (1984) e, depois dele, Freuler (1997) denominam "crise de identidade da Filosofia". A suspeita lançada sobre a filosofia em geral, por conta do constrangedor fracasso da filosofia de matriz idealista — em especial sua vertente absoluta —, não somente atinge seus epifenômenos ou resultados, mas também coloca em dúvida o seu próprio estatuto no interior do corpo das ciências, assim como a sua validade e seu direito de existência. Como sintetiza Beiser:

4 Aplica-se aqui o mesmo caso da nota anterior. É Heidegger mesmo quem atesta a importância fundamental da tese de doutorado de Brentano, sobre os múltiplos significados de Ser - sob orientação de F. A. Trendelenburg - como impulso inicial para o desenvolvimento de suas próprias incursões referentes a esta questão (Heidegger, 2009). Sobre a relação Heidegger-Brentano, veja-se Volpi (1976).

5 Note-se também a existência de um revival de Aristóteles (e Platão) no mesmo século XIX, sendo tal retorno aos problemas e à obra do Estagirita um aspecto importante da própria formação e desenvolvimento de Kierkegaard. Sobre a importância de Aristóteles no século XIX, veja-se Thouard (2003).

6 No que diz respeito a Kierkegaard, Löwith possui bons insights e aponta aspectos bastante profícuos (veja-se, por exemplo, Löwith, 1964, pp. 148-149; 161). Infelizmente, tais pontos são apenas referenciados sem uma análise mais profunda. As relações entre Kierkegaard e Trendelenburg, concernentes à "Logische Frage", não são sequer mencionados.

7 Um caso paradigmático do tipo de reavaliação ao qual me refiro pode ser visto na querela entre $\mathrm{H}$. Sluga e M. Dummett acerca da interpretação de Frege. Sobre o debate Sluga-Dummett, veja-se Heis (2013). 
By the 1840s, however, this conception of philosophy [a hegeliana] had become completely discredited. Most intellectuals no longer believed it possible for philosophy to provide a foundation for the sciences through a priori means or rational excogitation alone. There was no confidence in self-evident first principles, intellectual intuitions, a priori construction, or even a dialectic. The foundationalist program had come under heavy criticism from several quarters: from the 'physicalists' (Justus Liebig, Emil du Bois Reymond, Hermann Helmholtz); from the early neo-Kantians (Fries, Herbart, Beneke); and from the later idealists (Lotze, Trendelenburg, and Hartmann). All seemed to concur on one central point: that general principles and a priori reasoning cannot by themselves provide concrete results. We cannot derive substantive conclusions from formal principles, determinate results from indeterminate premises. All content, all knowledge of existence, has to derive from experience alone. The foundationalist program of speculative idealism was condemned as a relapse into the bad old ways of pre Kantian rationalism (Beiser, 2014, p. 15, itálico meu).

No interior desse quadro, os problemas referentes às categorias apresentamse como um dos loci mais privilegiados para compreender-se a crítica dirigida aos fundamentos da filosofia hegeliana. Não por acaso, há no período uma profusão de escritos sobre tais problemas. Para além da incontornável "Geschichte der Kategorienlehre" (1846) de F. A. Trendelenburg, em dois volumes, ${ }^{8}$ a segunda metade do XIX conheceu o opúsculo de H. Bonitz - "Über die Kategorien des Aristoteles" (1853), em confronto com a interpretação de Trendelenburg - e a "Kategorienlehre", de Eduard von Hartmann (1896). Anos mais tarde, no início do século XX, tanto a "Die Logik der Philosophie und die Kategorienlehre", de E. Lask (1911), quanto a obra póstuma de Brentano - "Kategorienlehre" (19071917) - revisitariam o tema. ${ }^{9}$ Mas então, de fato, por que há uma premência do problema das categorias na filosofia do XIX e, mais especificamente, a seguirmos a tese de Beiser, a partir de $1840 ?^{10} \mathrm{E}$, mais particularmente, por que Kierkegaard vê no exame de certas categorias a chave para o problema da relação entre lógica e ontologia? Para responder adequadamente a essas questões, é fundamental voltarmo-nos à configuração desse problema no interior da filosofia de Hegel.

8 Para além da História das Categorias e de sua opera magna de 1840 - "Logische Untersuchungen" -, Trendelenburg dedicou ao tema das categorias uma publicação de uma locução na Universidade de Berlim - "De Aristotelis categoriis" (1833) - e uma seleção de textos de Aristóteles acompanhados de comentários, os "Elementa Logica Aristoteleae" (1836). Sobre a tese interpretativa de Trendelenburg sobre as categorias de Aristóteles, veja-se o ensaio introdutório de G. Reale em Trendelenburg (1994, pp. 15-70) e Giusti (2012).

9 No marco dos trabalhos sobre as categorias e suas relações para com o desenvolvimento da filosofia posterior, lembre-se ainda do trabalho de habilitação de Heidegger, precisamente sobre a teoria das categorias e do sentido de Duns Scotus (Heidegger, 1978).

10 Beiser aponta diversas razões para localizar o início do período que se caracteriza mais propriamente como "após Hegel" no ano de 1840: é o ano da publicação das "Logische Untersuchungen" de Trendelenburg, assim como o ano em que H. Lotze termina sua "Metaphysik", "two books which broke utterly with the Hegelian heritage and which pushed metaphysics in a new direction" (2014, p. i). 
De início, é importante compreender o núcleo central do categorialismo, que remonta a Aristóteles. A ideia de um sistema ou rol de categorias fundamenta-se na solução da questão sobre a existência ou não de predicados mais gerais dos entes. Uma vez que, como aponta Aristóteles, é possível predicar os entes de conceitos cada vez mais abrangentes, irrompe a pergunta sobre a existência de um predicado mais geral ou que exprima um "gênero supremo" (cf. Aristóteles, 1998, 998b) do qual todos os entes possam ser predicados. Com a refutação da possibilidade de que "ser" seja tal gênero supremo, uma vez que as distinções no interior do gênero devem ser feitas a partir de diferenças que estejam fora do mesmo gênero e fora do ser não há nenhum predicado possível, Aristóteles apresenta então uma lista de dez gêneros supremos, as dez categorias (cf. Aristóteles, 1938, 1b 25). É possível ver, já aí, ao menos duas importantes questões. A primeira delas, que poderíamos chamar de problema genético, acerca da origem de uma tal lista de categorias, ou seja, se elas seriam, de algum modo, contrapontos mentais da estrutura mais geral da realidade ou conceitos espontâneos do intelecto que, por sua vez, conformariam a experiência adequando-a justamente àqueles conceitos; relacionada a tal problema genético está a questão, por assim dizer, metodológica ou de justificação. O segundo problema tradicional consiste justamente na discussão, por assim dizer, material, de quais seriam as categorias corretas, ou ainda, quais seriam, efetivamente, as categorias. ${ }^{11}$

Do que foi dito até agora, já se pode notar que, em seus pontos mais centrais, as questões referentes às categorias deixam-se reduzir, por sua vez, ao problema mais originário da relação entre ser e pensamento. Seja qual for a resposta dada à primeira das duas questões expostas acima, isto é, sejam as categorias conceitos provenientes de abstrações das estruturas mais fundamentais da realidade e dos entes, sejam conceitos espontâneos do entendimento, o que está em jogo, no limite, é o problema acerca do modo como se opera o contato entre o pensamento e a realidade. $\mathrm{O}$ mesmo se dá em relação à segunda das questões; quaisquer que sejam as categorias, estas - e não outras - constituiriam as estruturas mais basilares da intelecção do real ou ao menos o modo pelo qual o intelecto espontaneamente o concebe. É enfim, por isso, que de Kant a Hegel e, além dele, a filosofia do XIX, debruça-se com particular interesse sobre as categorias. Elas constituem uma resposta acerca dos axiomas de qualquer

11 Para um exemplo contemporâneo de tratamento desses dois problemas na confecção de um sistema das categorias, veja-se Chisholm (1996). Para uma análise mais geral sobre a própria natureza das categorias, veja-se o interessante ensaio de Van Inwagen (2014). Para uma análise histórico-sistemática dos problemas das categorias, veja-se Haaparanta e Koskinen (2012). 
sistema filosófico que deve assumir determinada posição acerca da relação entre pensamento e ser.

No que diz respeito a Hegel, a proeminência dos problemas relativos às categorias não poderia ser mais evidente. $\mathrm{O}$ centro gravitacional e irradiador de sua filosofia, exposto na "Wissenschaft der Logik" - como também na assim chamada "Lógica enciclopédica" -, pode ser descrito como a tentativa de solução última daqueles dois problemas descritos acima. No prefácio à segunda edição da "Ciência da Lógica", escrito poucos dias antes de sua morte em 1831, Hegel afirma que

Em tudo que o homem interiorize, em tudo que de uma forma ou de outra se torna para ele uma representação, em qualquer coisa que torne sua, ali há a linguagem penetrada e tudo o que ele transforma em linguagem e expressa nela contém uma categoria, seja oculta, misturada ou bem definida. A lógica é tão natural ao homem que é, de fato, sua própria natureza (Hegel, 2010, p. 12 / WL 21, p. 10). ${ }^{12}$

Hegel reconhece aí não apenas um papel fundamental desempenhado pela linguagem, mas, ao fazê-lo, desvela a estrutura essencialmente categorial da intelecção e, para além disso, da própria constituição do mundo. Com a afirmação de tal premência, não é surpresa que a depuração das respostas àquelas duas questões centrais deva passar ao primeiro plano da investigação filosófica. Como explicita o filósofo de Jena,

Como impulsos, as categorias desempenham seu papel apenas instintivamente; elas são trazidas à consciência uma a uma e assim são variáveis e mutuamente confundíveis, concedendo ao espírito apenas uma realidade incerta e fragmentária. Purificar [reinigen] essas categorias e elevar o espírito à verdade e à liberdade é, portanto, a mais alta atribuição da lógica (Hegel, 2010, p. 17 / WL 21, p. 16).

Ao fazer da purificação (reinigen) das categorias a mais alta (das höhere) atribuição da lógica, Hegel, ao mesmo tempo que apresenta o programa de sua própria filosofia, endereça uma crítica pontual ao tratamento kantiano sobre tais problemas. Um excerto da Lógica enciclopédica exibe claramente, mas não sem certa ironia, como Hegel interpreta o intento kantiano:

Como é bem conhecido, a filosofia kantiana portou-se muito à vontade no descobrimento das categorias. O Eu, a unidade da consciência-de-si, é totalmente abstrato e completamente indeterminado; como, pois, chegar às determinações do Eu, das categorias? Felizmente na lógica habitual já se encontram empiricamente dadas, as 
diversas espécies de juizos. Ora, julgar é pensar um objeto determinado. As diversas maneiras de julgar, já bem enumeradas, fornecem portanto as diversas determinações do pensar (Hegel, 1995, §42, itálicos meus).

Se, por um lado, Hegel concorda com Kant na necessidade de se empreender uma dedução ou derivação das categorias independente da experiência, ao invés da elaboração de uma lista "rapsódica", como teria feito Aristóteles de acordo com o filósofo de Königsberg (cf. Kant, 2001, A 81), por outro, segundo Hegel, Kant não teria levado a tarefa ao exigido grau de radicalidade, uma vez que não se trata apenas de exibir uma dedução mais sistemática das categorias, senão de fazer com que elas emirjam necessariamente do pensamento não apenas como conceitos dos objetos em geral (cf. Kant, 2001, B 128), mas como formas autogeradas pela razão que, simultaneamente, mostram-se como as estruturas (materiais) últimas do real que se apresentam como tais na medida em que ser e pensar avançam na tarefa de mútua determinação dialética. Para Hegel, Kant estava certo em perceber o $E u$ como fonte e origem das categorias. Estava errado, contudo, em ao menos dois outros pontos. Primeiramente, assumir acriticamente as formas dos juízos como caminho para a derivação das categorias não apenas fez com que Kant não tenha se afastado da "lógica tradicional", mas o manteve numa compreensão meramente formal das categorias, na qual elas são tão somente as formas possíveis dos objetos da experiência e não guardam relação necessária para com seu conteúdo. Como resultado último daquela supracitada falta de radicalidade, sob a perspectiva de Hegel, Kant preocupou-se apenas com o caráter epistemológico-formal das categorias, não atentando para a necessária dimensão ontológico-material. De fato, para Kant, as categorias são derivadas das quatro "funções do pensamento" que encontramos justamente "se abstrairmos de todo o conteúdo de um juízo em geral e atendemos apenas à simples forma do entendimento" (Kant, 2001, B 95). Assim, como aponta Hegel,

\begin{abstract}
A filosofia crítica submete então a exame, antes de tudo, o valor dos conceitos-doentendimento utilizados na metafísica, e, aliás, também nas outras ciências e na representação ordinária. No entanto, não se dirige essa crítica ao conteúdo e à relação determinada, dessas determinações-de-pensamento entre si, mas considera-se segundo a oposição de subjetividade e objetividade em geral (Hegel, 1995, §41).
\end{abstract}

Dessa forma chegamos ao sentido final da empresa hegeliana na lógica e, finalmente, ao ponto que detém o maior interesse para a acima mencionada premência da questão das categorias no contexto da virada anti-Hegel no XIX e, por conseguinte, para o problema que Kierkegaard vê na filosofia de "seu tempo". O que Hegel pretende com sua Lógica é, em última análise, mostrar que aqueles conceitos mais gerais porque mais indeterminados do pensamento e 
aparentemente apenas formais - as categorias -, podem e devem ser conduzidos progressivamente às suas determinações a partir de si mesmas; é essa a função motriz da dialética. ${ }^{13}$

O que aqui nos interessa é, no entanto, a tese que simultaneamente sustenta e é resultado do empreendimento da Lógica. Se para Hegel as determinações mais concretas da realidade podem ser alcançadas dialeticamente a partir das categorias mais gerais com as quais a lógica começa, isso significa não apenas a superação da já mencionada limitação da filosofia kantiana, mas igualmente a afirmação fundamental da unidade radical entre ser e pensamento, uma vez que não há nenhum sentido de ser que permaneça externo à lógica ou, ainda, que não figure como um dos momentos do desenvolvimento dela. Tal unidade perpassa toda a Lógica e é afirmada desde sua "Introdução", precisamente sob a égide da superação daquela distinção entre os aspectos formais e materiais nas categorias:

Mas o que é usualmente entendido por lógica é considerado com total desconsideração de uma significação metafísica. Essa ciência, no estado em que ela ainda se encontra, confessadamente não possui qualquer conteúdo do tipo que a consciência ordinária aceitaria como realidade ou como fato genuíno. [...] e uma concreção acerca dessas determinações abstratas, assim como tal ser substancial, é comumente procurada para elas fora delas mesmas. Mas a razão lógica é ela mesma o fator real ou substancial que, dentro de si mesma, mantém juntas todas as determinações abstratas e constitui sua unidade própria e absolutamente concreta. Não há necessidade, portanto, de procurar em toda parte por aquilo que costumeiramente se chama uma matéria; não é culpa da lógica se esta parece vazia, mas apenas da maneira com que esse tópico é tratado (Hegel, 2010, pp. 27-28 / WL, 21, p. 32).

Tal tese perpassa toda a obra e aparece em reafirmações daquela mesma unidade, tal como:

Mas na Introdução, o conceito de lógica foi ele mesmo apresentado como o resultado de uma ciência que o transcende, e assim como igualmente uma pressuposição. Desse modo, a lógica foi definida como a ciência do pensamento puro - a ciência que tem o pensamento puro por seu princípio e que é uma unidade que não é abstrata mas viva e concreta, de modo que a oposição que faz a consciência entre um ser subjetivamente existente para si e outro ser objetivamente foi superada nela, e o ser é conhecido como sendo ele próprio um puro conceito e o puro conceito sendo o verdadeiro ser. Esses são, então, dois momentos contidos na lógica. [...] Assim, é todo o conceito que nós devemos considerar, primeiro como um conceito existente, e então como conceito; em

13 Note-se que Kierkegaard, na esteira da crítica de Trendelenburg, não apenas reconhece como lança mão do argumento contra tal intrusão de tal motricidade na lógica. Veja-se, por exemplo, Kierkegaard (1992 / SKS 7 / SKS 4). "SKS" refere-se ao volume da obra na mais recente edição crítica da obra de Kierkegaard em dinamarquês (Kierkegaard, 1997-2012). 
um caso ele é conceito apenas implicitamente, em si, o conceito de realidade ou ser, em outro, ele é o conceito enquanto tal, o conceito que existe para si (Hegel, 2010, pp. 38-39 / WL 21, p. 45).

Note-se que o que Hegel afirma não é uma mera unidade arbitrária entre as duas dimensões, mas sim que a estrutura íntima do real consiste em determinações categoriais plenamente cognoscíveis pela razão a partir de categorias mais indeterminadas expostas na Lógica e que, por isso, esta transcende a si mesma ao capturar o real em sua constituição no interior do movimento dialético. Dito de outro modo, o ser possui uma forma lógica, uma vez que é "o puro conceito que é o momento mais íntimo [das Innerste] dos objetos" (Hegel, 2010, p. 17 / $W L$ 21, p. 15). Assim, é na profunda unidade entre lógica e ontologia que se manifesta o cerne da filosofia hegeliana e que aparece como o problema fundamental que Kierkegaard denuncia como necessitando de esclarecimento. ${ }^{14}$

\section{Iluminando a relação entre lógica e ontologia: Kierkegaard e o problema das categorias}

A partir da exposição feita acima, tornam-se mais claros os motivos da grande ocorrência de escritos sobre o tema das categorias a partir de 1840. A oposição à filosofia hegeliana encontra aí, no núcleo que sustenta o sistema, simultaneamente a pedra angular e a pedra de toque. Não por acaso, a crítica à identidade entre a ontologia e a lógica, tal como concebida por Hegel, enseja igualmente um amplo movimento de reflexão sobre o estatuto e a fundamentação da própria lógica no século XIX, em um arco de problemas que subsume nomes como Frege e Husserl. ${ }^{15} \mathrm{Se}$, a partir do contexto e da problemática que expusemos até aqui, voltarmos à citação de Kierkegaard que nos serve de mote, podemos notar que o filósofo dinamarquês não apenas ataca um problema profundo e amplo do ponto de vista da filosofia mais geral do XIX - circunstância que alarga o plano no qual Kierkegaard é usualmente visto - como aponta aquilo que, do seu ponto de vista, constitui o caminho de solução ou de esclarecimento dos erros que enxerga no modo como a relação entre lógica e ontologia se dão no pensamento hegeliano ou, de maneira mais geral, em "nosso tempo" (vor Tid). ${ }^{16}$

14 Sobre a unidade entre lógica e ontologia em Hegel, veja-se Redding (2012).

15 Apenas a título de nota, tenha-se em mente que o psicologismo, combatido duramente por ambos, tem em Jakob Fries um de seus precursores e que seu psicologismo era, precisamente, "a reaction against and a reformation of what was seriously taken as the errors and excesses of Hegel's arguments in the Science of Logic" (Kirkland, 1993, p. 219).

16 Acerca do interesse kierkegaardiano pelo problema das categorias modais, deve-se registrar o bom trabalho de A. Come (1991). No entanto, Come não se interessa por inserir Kierkegaard no contexto de problemas da filosofia do XIX de maneira mais ampla. 
Em 1847, dois anos depois da entrada sobre a relação entre lógica e ontologia, Kierkegaard volta a registrar o interesse pelo tema das categorias em seus diários:

Não há filósofo moderno do qual eu tenha mais aproveitado do que de Trendelenburg. [...] Minha relação com ele é muito especial. Parte do que me ocupou [beskaeftiget] por um longo tempo foi toda a doutrina das categorias (os problemas relativos a isso encontram-se em minhas notas antigas, em pedaços de papel quarto). E agora Trendelenburg escreveu dois tratados sobre a doutrina das categorias que eu estou lendo com extremo interesse (Pap. VIII1 A 18, 1847 / SKS 20, 93).

Os "tratados" de Trendelenburg, em relação aos quais Kierkegaard manifesta extremo (yderste) interesse, são os dois volumes da já mencionada "Geschichte der Kategorienlehre", publicada um ano antes. No entanto, o aspecto mais interessante do testemunho de Kierkegaard é que, por meio dele, somos informados de que o filósofo se interessara há tempos pela "doutrina das categorias" (Lcere om Kategorierne) e nos direciona a "antigas notas" sobre o tema. Tais notas são um conjunto de nove declarações, questões e teses, ao modo de aforismos, que datam de 1842-1843:

a) Pode haver uma transição de uma qualificação quantitativa para uma qualitativa sem um salto? E todo o resto da vida não desempenha nenhum papel nisso? (Pap. IV C 87 n.d., 1842-43 / SKS 27, 269);

b) Toda determinação [Bestemmelse] para a qual ser [Voeren] é uma qualificação essencial repousa fora do pensamento imanente e, consequentemente, fora da lógica. (Pap. IV C 88 n.d., 1842-43 / SKS 27, 269);

c) Em que medida a imaginação desempenha um papel no pensamento lógico; e a vontade; em que medida a conclusão é uma resolução. (Pap. IV C 89 n.d., 1842-43 / SKS 27, 269);

d) Qual é a significação histórica da categoria? O que é uma categoria? (Pap. IV C 90 n.d., 1842-43 / SKS 27, 269);

e) As categorias devem ser derivadas do pensamento ou do ser? (Pap. IV C 91 n.d., 1842-43 / SKS 27, 269);

f) Qual é a relação entre o sujeito especulativo e a existência histórica? Qual é a sua continuidade? Qual é a prioridade? (Pap. IV C 92 n.d., 1842-43 / SKS 27, 269);

g) Como isso está relacionado com o desenvolvimento histórico-mundial tão citado atualmente? (Pap. IV C 93 n.d., 1842-43 / SKS 27, 269); 
h) Uma transição patética - uma transição dialética (Pap. IV C 94 n.d., 1842-43 / SKS 27, 269). ${ }^{17}$

Se é verdade que Kierkegaard não construiu a sua própria Lare om Kategorier - Doutrina das Categorias - plenamente acabada, como outros no século XIX, há aí mais do que apenas traços ou indicações gerais; há teses fundamentais para grande parte do pensamento kierkegaardiano posterior:

i) "Qualidade" e "Quantidade" são, elas próprias, categorias (Aristóteles) ou espécies de categorias (Kant). A relação entre elas, bem como sua ordenação, já chamava a atenção de Kierkegaard no mesmo período, por uma razão singular: "Por que Kant começou com a quantidade e Hegel com a qualidade?" (Pap. IV C 63 / SKS 19, 406). Do mesmo modo, a tese sobre a descontinuidade entre as dimensões quantitativa e qualitativa e a consequente "metabasis eis allo genos" - ou salto (a) - quando da transição de uma para outra é recorrente e faz parte da crítica a Hegel (cf. Kierkegaard, 1985, p. 98, bem como a seção "Tornar-se subjetivo" (Kierkegaard, 1992, pp. 129-188). Igualmente, a questão da distinção entre transição patética e transição dialética (h) só pode ser compreendida nesse contexto.

ii) Que todas as determinações relativas ao "ser" devam estar fora do âmbito do pensamento e, portanto, da lógica, é uma das pedras angulares da posição kierkegaardiana e de sua crítica ao idealismo absoluto de "seu tempo". Para se compreender a concepção que Kierkegaard tem de "ser", é preciso atentar para a centralidade da distinção entre Realidade (Realitet) e Atualidade (Virkelighed). Em si mesma, tal diferenciação não é originalmente kierkegaardiana, senão que remonta à distinção clássica entre Realitas e Actualitas - e ao debate sobre a distinção entre essentia e existentia -, que, por sua vez, é recepcionada nas metafísicas de Wolff e Leibniz e compreende Realitas não como a existência concreta, mas como o conjunto de atributos ou propriedades de uma coisa (res), distinta assim da existência efetiva ou atual desta coisa, sua Actualitas, esta sim sua existência efetiva. Hegel mesmo, na "Ciência da Lógica", comenta sobre a equivocidade do termo "realidade": "Realidade pode parecer uma palavra ambígua, uma vez que ela é usada para determinações diferentes, até mesmo opostas" (Hegel, 2010, p. 86 / WL 21, p. 99). Kierkegaard faz abundante uso dessa distinção, que aparece sob diversas formulações até encontrar no "Pós-

17 Em outra entrada da mesma época, consignada em outro caderno, lê-se ainda: "O que é uma categoria? Até onde posso dizer, a [filosofia] moderna não ofereceu nenhuma definição sobre isso. Hegel não o fez, de forma alguma; com a ajuda de sua marcha inversa [inverse Gang], ele sempre o deixa para a virtuosidade do leitor fazer o mais difícil, juntar a multiplicidade na energia de um pensamento [at samle det Mangfoldige i een Tankes Energie]" (Pap. IV C 63 / SKS 19, 406). 
escrito" sua expressão explícita como diferença entre Realidade (Realitet) e Atualidade (Virkelighed).${ }^{18}$ Dessa forma, ao afirmar que, no que diz respeito às determinações nas quais "ser" é um traço essencial, tais determinações devem ter lugar fora do domínio da lógica, Kierkegaard está se referindo a "ser" fundamentalmente como ser qua atual que não pode ser identificado ou reduzido ao ser qua pensado:

Este triunfo do pensamento puro (que nele pensamento e ser são um) é tanto risível quanto lamentável, porque no pensamento puro realmente não há questão de diferença. - A filosofia grega assumia como algo natural que o pensamento tivesse realidade [Realitet]. Ao refletir sobre isso, pode-se chegar ao mesmo resultado, mas por que a realidade-pensada [Tanke-Realitet] é confundida com a atualidade [Virkelighed]? Realidade-pensada é possibilidade, e o pensamento deve apenas rejeitar qualquer questionamento sobre se ele é atual (Kierkegaard, 1992, p. 328 / SKS 7, 299).

iii) Se a Existência é, fundamentalmente, ser qua atual (Virkelig) e a atualidade qua atualidade (Virkelighed) não pode ser apreendida pelo pensamento senão sob o preço de ser convertida em ser qua pensado, isto é, em seu preciso oposto, possibilidade (Mulighed) (cf. Kierkegaard, 1992, p. 314), há ao menos um aspecto do ser - o atual - que interdita sua intrusão na lógica. No entanto, “'[...] modernamente a lamentável confusão é que 'atualidade' [Virkelighed] foi incluída na lógica e então, distraidamente, esquece-se que 'atualidade' em lógica é, no entanto, apenas 'atualidade pensada' [toenkt Virkelighed], i.e., é possibilidade [Mulighed]”. (Pap. X2 A 439 / SKS 23, 72). ${ }^{19}$ A crítica a uma concepção de identidade entre lógica e ontologia é uma posição tão importante na arquitetura do pensamento de Kierkegaard que mesmo em 1850, época na qual a tradição interpretativa considera que o filósofo dinamarquês estaria às voltas apenas com as obras de conteúdo eminentemente cristão ou edificante, Kierkegaard volta ao tema em uma nova entrada de seus diários:

O que confunde toda a ideia de "essência" na lógica é que não é dada a atenção ao fato de que se opera continuamente com o "conceito" existência. Mas o conceito existência é uma idealidade, e a dificuldade é precisamente se a existência é absorvida no conceito. [...] Kant está certo em dizer "a existência não traz nenhum novo predicado ao conceito". Obviamente, Kant pensa honestamente na existência não como absorvida no conceito, existência empírica. Em toda relação de idealidade permanece verdadeiro que essentia é existentia [...]. A afirmação leibniziana: se Deus é possível, ele é necessário - está

18 Veja-se, por exemplo, a distinção entre "ser ideal [ideel Væren]" e "ser factual [faktisk Væren] em Kierkegaard (1985, pp. 41-42n / SKS 4, 246n), ou a diferenciação entre "realidade pensada [Tanke-Realitet] e Atualidade [Virkelighed] em Kierkegaard (1992, p. 328 / SKS 7, 299). Ver também Kierkegaard (1980, p. 11 / SKS 4, 318-319). Sobre tal distinção, veja-se Ferreira (2015).

19 Para uma síntese do conceito de Lógica em Kierkegaard, veja-se Ferreira (2014a). 
inteiramente correta. Nada é adicionado ao conceito se ele tem existência ou não; é uma questão de completa indiferença; de fato, ele tem existência, i.e., existência-conceito [Begrebs-Existents], existência ideal [ideal Existents]. Mas existência corresponde ao individual, como Aristóteles já ensinou, e o indivíduo permanece exterior e não é absorvido no conceito (Pap. X2 A 328 n.d., 1849-50).

Como se pode depreender daí, o ponto nevrálgico que constitui a necessidade de iluminação da tese da identidade entre lógica e ontologia é que há ao menos uma determinação ontológico-categorial que não pode ser derivada exclusivamente pelo intelecto a partir de momentos determinantes mais gerais, a saber, o ser qua atual.

iv) Quanto ao papel da imaginação [Phantasien] no pensamento lógico (c), Kierkegaard volta ao tema no "Pós-escrito" no contexto da crítica à lógica hegeliana. Na exposição da terceira das condições para um sistema lógico, Kierkegaard repete ali a questão: "Seria desejável se, para lançar uma luz sobre a lógica [over Logiken], a gente se orientasse psicologicamente a respeito do estado anímico daquele que pensa o lógico [det Logiske], que espécie de morrer a si mesmo se requer para tanto, e até que ponto a imaginação desempenha um papel nisso." (Kierkegaard, 1992, p. 117 / SKS 7, 113). O sentido último de tal pergunta fica claro a partir do recurso ao argumento que Trendelenburg endereça à lógica de Hegel no que diz respeito à pressuposição não tematizada do pensamento figurativo sob a forma de intuição (Anschauung): "Mas o pensar puro só vive do pensar figurativo, impuro. Se ele não recebe deste o seu pão de cada dia, definha sem salvação" (Trendelenburg, 1843, p. 189-190). ${ }^{20}$

v) A questão sobre a definição de categoria, bem como de sua importância histórica, reforça tanto a recepção do problema quanto sua premência, sobretudo em conexão com o problema correlato da origem das categorias (e). Ao perguntar se as categorias devem ser derivadas do pensamento ou do ser, Kierkegaard não apenas mostra compreender os dois grandes momentos historicamente determinados desse problema - em Aristóteles e Kant -, mas, podemos dizer, coloca o problema a si mesmo. Por força de (b) e de todo o comprometimento ontológico daí derivado, Kierkegaard não pode conceder que as categorias eminentemente existenciais sejam, qua existenciais, derivadas do pensamento sob pena de recair precisamente no erro do qual acusa Hegel. Antes, se elas são ou devem ser determinações da existência, não podem ser exclusivamente derivadas do intelecto - como no projeto hegeliano - a partir de categorias

20 Kierkegaard também conhece o argumento da participação da intuição/imaginação no processo dialético a partir de Schelling, e menciona-o ao menos duas vezes (Kierkegaard, 1992, p. 335 / SKS 7, 306; Kierkegaard, 1980, p. 11/ SKS 4, 319). Sobre este ponto, veja-se Ferreira (2014b). 
mais gerais ou menos determinadas. No entanto, ao elaborar uma exposição dessas categorias, como de fato o faz em diversas obras, o filósofo dinamarquês assume tais determinações existenciais como categorias de um pensamento ainda que não sistemático - sobre a existência. Tal tensão é o cerne mesmo daquilo que chama de sua "Ciência Existencial" [Existentiel-Videnskab] (Pap. IV C 100 n.d., 1842-43 / SKS 27, 271). Se para o idealismo a dedutibilidade das categorias, ou seja, que elas possam ser compreendidas e sua lista elaborada $a$ priori, é um aspecto decisivo para o seu projeto, para a perspectiva existencial de Kierkegaard a operação fundamental deve ser precisamente a inversa.

\section{Conclusão}

Se o périplo percorrido até aqui estiver correto, é possível entrever dois outros pontos prementes, sendo um deles mais geral e outro de caráter interno à obra de Kierkegaard.

Em se tratando da dimensão interna, a posição acerca do tratamento das categorias deve ter impacto retroativo sobre a concepção das próprias categorias genuinamente kierkegaardianas, tais como Angústia, Desespero, Self, Paradoxo, que compõem a sua, por assim dizer, tábua de categorias existenciais. Uma investigação do comprometimento ontológico de Kierkegaard e do estatuto e validade epistemológicos de tais conceitos é uma tarefa hermenêutica a ser empreendida. ${ }^{21}$

Do ponto de vista do contexto mais geral dos problemas filosóficos do século XIX, a exposição sobre a importância do tema das categorias no pensamento de Kierkegaard deve ao menos colocar em perspectiva a visão tradicional que enxerga no filósofo dinamarquês alguém à margem dos desdobramentos mais centrais ocorridos na filosofia do período. Basta atentar para a centralidade das discussões lógico-ontológicas da época para verificar que, se não diretamente, Kierkegaard tem sólidas contribuições para alguns dos debates mais fecundos e, do mesmo modo, tal universo de problemas não pode permanecer ausente da literatura interpretativa kierkegaardiana.

\section{Referências}

ARISTÓTELES. "Categories. On interpretation. Prior analytics”. Cambridge: Harvard University Press, 1938. 
Madrid: Gredos, 1998.

" "Metafísica de Aristóteles - edición trilíngue". Tradução de V. G. Yebra. BEISER, F. C. "Late German Idealism: Trendelenburg and Lotze”. Oxford: Oxford University Press, 2013.

. "After Hegel”. New Jersey: Princeton University Press, 2014.

"The Genesis of Neo-Kantianism, 1796-1880". Oxford: Oxford University

Press, 2015.

CHISHOLM, R. M. "A realistic theory of categories - an essay on ontology". New York: Cambridge University Press, 1996.

COME, A. B. “Trendelenburg's Influence on Kierkegaard's Modal Categories”. Montreal: Inter Editions, 1991.

DUMMET, M. “Origins of analytical philosophy”. New York: Harvard, 1996.

FERREIRA, G. “Logic”. (pp. 97-104). In: S. M. Emmanuel, W. McDonald, J. Stewart (orgs.). Kierkegaard Research: Sources, Reception and Resources - Kierkegaard's Concepts - vol. 15 - Tome IV: Individual to Novel. Surrey: Ashgate, 2014a.

"Kierkegaard Descends to the Underworld: Some remarks on the Kierkegaardian appropriation of an argument by F. A. Trendelenburg”. Cognitio, Vol. 14, Nr. 2, pp. 235-246, 2014b.

. "The Philosophical Thesis of the Identity of Thinking and Being is Just the Opposite of What it seems to be.' Kierkegaard on the Relations between Being and Thought". Kierkegaard Studies Yearbook, Vol. 20, pp. 13-30, 2015.

FREULER, L. "La crise de la philosophie au XIXe siècle”. Paris: Vrin, 1997.

FRIEDMAN, M. “A parting of ways - Carnap, Cassirer, and Heidegger”. Chicago; La Salle: Open Court, 2000.

GIUSTI, E. "Lógica, linguagem e ontologia no século XIX: a interpretação das categorias de Aristóteles por Adolf Trendelenburg”. Revista Guairacá, Nr. 28, pp. 93-111, 2012. GLOCK, H-J. (org.). "The rise of analytical philosophy”. Oxford: Blackwell Publishers, 1997.

HAAPARANTA, L; KOSKINEN, H. J. (eds.). "Categories of being: essays on metaphysics and logic". New York: Oxford University Press, 2012.

HANNAY, A.; MARINO, G. (org.). "The Cambridge companion to Kierkegaard". Cambridge: Cambridge University Press, 1998.

HEGEL, G. W. F. "Wissenschaft der Logik: die objektive Logik (1832)". In: HEGEL, G. W. F. Gesammelte Werke. Hamburg: Felix Meiner, 1978. Vol. 21.

. "Enciclopédia das ciências filosóficas em compêndio - I: A ciência da lógica". Tradução de P. Meneses. São Paulo: Loyola, 1995.

" "Science of Logic". Tradução de G. Di Giovanni. New York: Cambridge University Press, 2010.

HEIDEGGER, M. "Duns Scotus' theory of the categories and of meaning”. Tradução de H. J. Robbins. De Paul University, Ph.D. Dissertation, 1978.

. "O meu caminho na fenomenologia". Tradução de A. Falcato. Covilhã: LusofiaPress, 2009. 
HEIS, J. "Frege, Lotze, and Boole". In: RECK, E. (org.). The Historical Turn in Analytic Philosophy. New York: Palgrave, 2013.

KANT, I. "Crítica Da Razão Pura”. Lisboa: Fundação Calouste Gulbenkian, 2001. KIERKEGAARD, S. "Søren Kierkegaards Papirer”. Vols. 1-16, editado P. A. Heiberg, V. Kuhr, e. Torsting. Copenhagen: Gyldendal, 1909-48; complementado por Niels Thulstrup. Copenhagen: Gyldendal 1968-78.

. "The Concept of Anxiety". Tradução de R. Thomte e A. B. Anderson. Princeton, New Jersey: Princeton University Press, 1980.

. "Philosophical Fragments; Johannes Climacus, or De omnibus dubitandum est”. Tradução de H. V. Hong e E. H. Hong. Princeton, New Jersey: Princeton University Press, 1985.

. "Concluding Unscientific Postscript". Vol. 1, tradução de H. V. Hong e E. H. Hong. Princeton, New Jersey: Princeton University Press, 1992.

. "Søren Kierkegaards Skrifter". Editado por N. J. Cappelørn, J. Garff, J. Knudsen,

J. Kondrup e A. McKinnon. Copenhagen: Gad Publishers, 1997-2012. 56 Vols.

KIRKLAND, F. M. "Hegel's critique of psychologism". In: KIRKLAND, F. M.; CHATTOPADHYAYA, P. (orgs.). Phenomenology - East and West. Springer, pp. 219244. 1993.

KISIEL, T. "The genesis of Heidegger's Being and Time". Berkeley: University of California Press, 1993.

LIEBMANN, O. "Kant und die epigonen". Stuttgart: Carl Schoder, 1865.

LIPPITT, J.; PATTISON, G. (org.). "The Oxford handbook to Kierkegaard". Oxford: Oxford University Press, 2013.

LÖWITH, K. "From Hegel to Nietzsche - the revolution in nineteenth-century thought". New York: Columbia University Press, 1964.

MALIK, H. C. "Receiving Søren Kierkegaard: the early impact and transmission of his thought". Washington, D.C.: The Catholic University of America Press, 1997.

MOYAR, D. (org.). "The Routledge companion to nineteenth century philosophy". New York: Routledge, 2010.

O’HEAR, A. (ed.). “German philosophy since Kant”. Cambridge: Cambridge University Press, 1999.

POLITIS, H. "Kierkegaard en France au XXe siècle: Archéologie d'une reception". Paris: Éditions Kimé, 2005.

PORTA, M. A. G. “Zurück zu Kant - Adolf Trendelenburg, la superación del idealismo y los orígenes de la filosofía contemporánea”. Doispontos, Curitiba, São Carlos, Vol. 2, Nr. 2, pp. 35-59, 2005.

"Estudos neokantianos". São Paulo: Loyola, 2011.

REDDING, P. "The Relation of Logic to Ontology in Hegel”. In: HAAPARANTA, L; KOSKINEN, H. J. (eds.). Categories of being: essays on metaphysics and logic. New York: Oxford University Press, 2012. pp. 145-166.

SCHNÄDELBACH, H. "Philosophy in Germany - 1831-1933". Tradução de E. Matthews. Cambridge: Cambridge University Press, 1984. 
THOUARD, D. (org.). “Aristote Au XIXe Siècle". Villeneuve d'Ascq: Presses Universitaires du Septentrion, 2003.

TRENDELENBURG, A. "Die Logische Frage in Hegel's System. Zwei Sreitschriften". Leipzig: F. A. Brockhaus, 1843.

. "La dottrina dele categorie in Aristotele - com in appendice la prolusione accademica del 1833 'De Aristotelis categoriis'”. Tradução de V. Cicero. Milano: Vitae Pensiero, 1994.

VAN INWAGEN, P. “Meta-Ontology”. Erkenntnis, Vol. 48, Nr. 2/3, pp. 233-250, 1998. . "What is an ontological category?". (pp. 183-201). In: VAN INWAGEN, P. Existence - Essays in Ontology. New York: Cambridge University Press, 2014.

VOLPI, F. "Heidegger e Brentano - l'aristotlismo e il problema dell'univocitá dell'essere nella formazione filosofica del giovane Martin Heidegger". CEDAM: Padova, 1976. 